\title{
Successful Management of Massive Obstetric Haemorrhage due to Placenta Previa/Accreta - A Case Report
}

\author{
S CHOWDHURYa, M RASHID ${ }^{\mathrm{b}}$
}

(J Bangladesh Coll Phys Surg 2011; 29: 46-48)

\section{Introduction:}

Placenta accreta in association with placenta previa and previous caesarean delivery is a condition of increasing clinical significance ${ }^{1}$. Bleeding from placenta previa/ accreta of the lower uterine segment, during caesarean section operation or its immediate postpartum period portrays a difficult management problem in obstetrics. Approach to control such a bleeding depends upon the individual case and includes uterine packing, bilateral uterine artery ligation, bilateral internal illiac artery ligation, trans-catheter arterial embolization, and hysterectomy ${ }^{2,3}$. One case of placenta previa/accreta with history of previous caesarean section with intractable postpartum bleeding is being reported here.

Keywords: Postpartum; Haemorrhage; Placenta previa/ accreta; Caesarean; Hysterectomy.

\section{Case Report:}

Mrs. Helena Khanam, a 35 years old, $2^{\text {nd }}$ gravid patient, serving as senior staff nurse in General Hospital, Tangail, was admitted in labour ward of Dhaka medical college hospital on $1^{\text {st }}$ of May, 2002 at 2:40am with the complaints of -

Severe per-vaginal bleeding following caesarean section and subtotal hysterectomy for 37 weeks of pregnancy with abdominal pain and gradual distension of abdomen

a. Dr. Shiuly Chowdhury, MBBS, FCPS (Gynae and Obs.), Resident Surgeon (Ex), Bangladesh Medical College, Dhaka.

b. Prof. Dr. Maliha Rashid, , MBBS, FCPS (Gynae), Professor \& Head, Dept. of Obstetrics and Gynaecology, Dhaka Medical College \& Hospital, Dhaka.

Address of Correspondence: Dr. Shiuly Chowdhury, MBBS, FCPS (Gynae and Obs.), Resident Surgeon (Ex), Bangladesh Medical College, Dhaka, email: shiuly07@yahoo.com

Received: 25 August, 2009

Accepted: 4 January, 2011 for 9 hours. Indication of caesarean section was previous caesarean section with placenta previa.

She was a booked case of Gynae. out-patient department in Tangail General Hospital with regular antenatal check up. She delivered her first child by caesarean section 11 years back. During this pregnancy her antenatal period was uneventful, and she was non-diabetic, normotensive. Routine ultrasonography report revealed that placenta was in the lower uterine segment (placenta previa). According to her date of last menstrual period, her expected date of delivery would have been $17^{\text {th }}$ of May 2002. So she was planned to deliver by caesarean section on $3^{\text {rd }}$ May of that year.

On $30^{\text {th }}$ April 2002, her labour pain started spontaneously. So she had undergone emergency caesarean section at 4:00 p.m. on the same day, and she delivered a mature healthy female baby. According to the operation note placenta was found morbidly adherent to the anterior wall of the lower uterine segment and also penetrated deeply through the uterine wall towards the urinary bladder. As the placenta was difficult to remove completely and uncontrollable bleeding started, so decision of subtotal hysterectomy was taken in the same sitting. The patient received 2 units of blood during her operation.

After half an hour following operation, she again started to bleed profusely per vaginally. Bleeding was so severe that she went to shock, and was managed by massive blood transfusion along with inj. Hydrocortisone, inj. Traxyl, inj. Adrenaline, inj. Caprolysin, and inj. Ergometrin. Condom catheterization was done in order to give compression over the remaining lower uterine segment. In the mean time, she received 23 units of blood and was referred to a renowned gynaecologist in a private clinic in Dhaka. 
On the way, she was unconscious, and was in shock, continuous blood transfusion and intravenous infusion was given via three intravenous channels. At the same time, she was also given inj. Hydrocortisone. Condom catheter was displaced there.

In the clinic, as the condom catheter was displaced, 3 mops were placed with an idea to pack the vagina. From there, she was immediately transferred to the labour emergency of Dhaka Medical College \& Hospital, and was accompanied by the attending gynaecologist.

In DMCH, the patient was found in shock with cool and clammy skin, disoriented and restless. Patient was severely anaemic. Crepitations were present over both lung bases. Abdomen was tense and distended, and flanks were full. Patient was catheterized, and her urine output was satisfactory. A decision of laparotomy was taken.

Laparotomy was done with sufficient support of blood. Abdomen was opened through the previous incision. On opening the abdomen, abdominal cavity was found filled with blood clots, which were removed. Peritoneal toileting was done. Uterine stumps were ligated again. Remaining portion of lower uterine segment was removed. Abdomen was closed in layers after keeping a drain in situ. During the whole procedure, her blood pressure was maintained with inj. Adrenaline and blood transfusion. The indwelling catheter was kept in situ. A vaginal pack was given. From operation theatre, she was transferred to the Intensive Care Unit (ICU) of DMCH.

On the way to the ICU, she developed cardiac arrest, and was resuscitated successfully.

In ICU the patient was kept under positive pressure ventilation for 48 hours. There she developed focal convulsion, and was treated with anticonvulsant. After establishment of spontaneous respiration, endotracheal tube was removed, and subsequently she regained her consciousness fully.

When her general condition became stable, she was transferred to respective unit of Obstetrics department. Her basal parameters were monitored routinely from time to time. Her haemoglobin percentage was measured on every alternate day, and accordingly, she was given another several units of blood. Her general condition improved gradually. Laparotomy wound remained healthy. Stitches were removed on $10^{\text {th }}$ POD.
Throughout the whole event, the patient received a total 36 units of blood.

\section{Discussion:}

The successful management of massive obstetric haemorrhage demands speed skill and experience ${ }^{4}$. The essential management of major bleeding episodes is the same whatever the underlying causes of haemorrhage and involves -

1. Identifying the cause and treating it to stop blood loss as well as

2. Replacing the circulating blood volume and other blood constituents ${ }^{5}$.

Placenta previa is more common in patients with a history of previous caesarean section with increasing incidence as the number of previous uterine scars increases ${ }^{1}$. Advancing age and parity are associated with the development of placenta previa, although the relative importance of these two factors is disputed ${ }^{6}$. Uterine scars, previous miscarriages, terminations, and dilatation and curettage are reported as predisposing factors, possibly due to endometrial damage ${ }^{7}$. There is an association between caesarean section scars and the subsequent development of placenta previa, which is reported as between $3 \%$ and $10 \%$ and increase with the number of previous caesarean section. This group of patients is also at risk of placenta accreta, which is stated at between $10 \%$ and $67 \%$, again increasing with the number of previous caesarean section ${ }^{6}$. In our case patient had delivered her first child by caesarean section and in her second pregnancy she had placenta previa.

The morbid adherence of the placenta to the uterus is termed placenta accreta. The penetration of the placenta upto the myometrium is termed placenta increta, when it penetrates the myometrium to the serosa, the term placenta percreta is used ${ }^{8}$. In our patient it was not suspected that the myometrial invasion had taken place until portions of the placenta could not be separated evenly by digital dissection.

Because of the poorly contractile nature of the lower uterine segment, trophoblastic invasion may give rise to uncontrollable haemorrhage following placental removal, even without histological confirmation of placenta accreta $^{9}$. In placenta accreta at emergency caesarean section attempts to remove the placenta are met with massive bleeding since no cleavage plane can be found ${ }^{10}$. 
The occurrence of an anterior placenta previa in a woman with a previous caesarean section scar should alert the obstetrician to the possibility of abnormal placental adherence. It is therefore prudent to warn the patient of the possibility of a caesarean hysterectomy in the event of uncontrollable haemorrhage ${ }^{11}$. There are several indications for emergency peripartum hysterectomy. The three most common reasons are uterine atony, placenta accreta and uterine rupture ${ }^{12}$. Majority clinicians in our country perform a subtotal or supracervical hysterectomy in most cases of emergency. As because there is a general belief that both operating time and blood loss are significantly lower with the subtotal technique. However even with this latter scenario, sometimes it is necessary to remove the cervix in case of placenta previa or placenta accreta involving the lower uterine segment. Somewhat surprisingly there is evidence that performance of a complete hysterectomy adds little to either operating time or blood loss ${ }^{12}$.

Our patient had an emergency subtotal hysterectomy for severe haemorrhage secondary to placenta previaaccreta but continued to bleed profusely. So relaparotomy was needed and removal of the remaining portion of uterus ultimately controlled bleeding. The caesarean section for placenta previa is therefore the domain of a senior obstetrician, who is in a position to proceed to a hysterectomy without the need to defer. Total hysterectomy should be the goal, although subtotal hysterectomy may be the only possibility ${ }^{11}$.

\section{Conclusion:}

In light of the increasing number of caesarean section, placenta previa and accreta will be more frequently encountered. In treating a patient who has had previous caesarean section and has a placenta previa, the clinician should consider the possible diagnosis of placenta accreta in advance which is a key to reduce maternal mortality. There should be a clear tested and tried protocol for dealing with massive obstetric haemorrhage. Adequate amount of blood must be in hand. Optimal management is a team work and requires the co-operation between obstetricians, anaesthetists, physicians, and haematologists.

\section{References:}

1. Weckstein LN, Masserman JS, Garite TJ. Placenta accreta: A problem of increasing clinical significance. Obstet Gynecol 1987;69:480.

2. Hallak M, Dildy GA, Hurly TJ, Moise KJ: Transvaginal pressure pack for life-threatening pelvic hemorrhage secondary to placenta accrete. Obstet Gynecol 1991;78: 938.

3. Robbie GF, Morgan MA, Payne GG, Wasemiller S: Logothetopulos pack for the management of uncontrollable postpartum hemorrhage. Am J Perinatol. 1990;7:327.

4. Seeley HF. Massive blood loss in obstetrics. In: Chamberlain G, editor. Turnbull's obstetrics. 2nd ed. Edinburgh: Churchill Livingstone; 1995. p. 744.

5. Maresh M, James D, Neales K. Critical care of the obstetric patient. In: James DK, Steer PJ, Weiner CP, Gonik B, editors. High risk pregnancy management options. 2nd ed. London: W. B. Saunders; 2000. p. 1291-1319.

6. Clark SL, Koonings PP, Phelan JP. Placenta previa/accreta and prior caesarean section. Obstet Gynecol, 1985;66:89-92.

7. Rose GL, Chapman MG: Aetiological factors in placenta previa - A case control study. British Journal of obstetrics and Gynecology. 1985;93:585-588.

8. Loeffler F. Postpartum haemorrhage and abnormalities of the third stage of labour. In: Chamberlain G, editor. Turnbull's obstetrics. 2nd ed. Edinburgh: Churchill Livingstone; 1995. p. 733.

9. Cunningham FG, MacDonald PC, Gant NF, Leveno KJ, Gilstrap LC, Hankins GDV, et al. Williams obstetrics. 20th ed. London: Prentice-Hall International; 1997. p. 760.

10. Klotz PG, Khalaff HM. Placenta percreta invading the bladder: report of 2 cases. J Urol 1989;141:938-938.

11. Manyoda IT, Varma TR. Massive obstetric hemorrhage due to placenta previa/accreta with prior caesarean section. Int J Gynaecol Obstet 1990;34:183-186.

12. Gilstrap III LC, Gant NF. Gynaecologic surgery for obstetrics patients A: obstetric problems. In: Rock JA, Thompson JD, editors. Te linde's operative gynaecology. $8^{\text {th }}$ ed. Philadelphia: Lippincott-Raven; 1997. p. 855-872. 